\title{
Analysis of Mie Gacoan Customer Loyalty through Customer Experience and Perceived Quality
}

\author{
Mellasanti Ayuwardani ${ }^{*}$, Bagus Yunianto Wibowo dan Nanang Adie Setyawan \\ Jurusan Administrasi Bisnis Politeknik Negeri Semarang \\ Email Korespondensi: mellasantiayuwardani@polines.ac.id
}

\begin{abstract}
ABSTRAK
Penelitian ini dilaksanakan untuk mengetahui loyalitas konsumen atau costumer loyalty pegunjung gerai Mie Gacoan melalui customer experience dan perceived quality di masa pandemi covid-19. Responden dalam penelitian ini adalah para pengunjung gerai Mie Gacoan dari pelajar maupun pekerja di kota semarang dengan sampel 100 responden dari keseluruhan populasi. Penelitian ini menggunakan alat analisis faktor konfirmatori dan maximum likehood estimation pada SEM (Structural Equations Modeling) dari paket statistik AMOS 24.0 (Analysis of Moment Structure). Teknik pengumpulan data menggunakan kuesioner dengan insidential sampling. Hasil estimasi parameter sesuai dengan hipotesis bahwa customer experience secara signifikan mempengaruhi costumer loyalty dengan nilai critical ratio (c.r) 4,666 dan $P$-Value ***, perceived quality berpengaruh positif terhadap costumer loyalty dengan nilai critical ratio (c.r) 5,926 dan P-Value ***. Dari penelitian ini dapat disimpulkan bahwa ditengah pandemi covid-19 saat ini para konsumen masih sangat antusias dan setia untuk datang membeli Mie Gacoan maupun pesan secara online walaupun banyak pesaing dalam bisnis kuliner sejenis.
\end{abstract}

Kata kunci: Customer Experience, Perceived Quality, Costumer Loyalty, Mie Gacoan

\section{ABSTRACT}

This research was conducted to determine consumer loyalty or customer loyalty of Mie Gacoan outlets through customer experience and perceived quality during the Covid-19 pandemic. Respondents in this study were visitors to Mie Gacoan outlets from students and workers in Semarang city with a sample of 100 respondents from the entire population. This study uses confirmatory factor analysis and maximum likelihood estimation on SEM (Structural Equations Modeling) from the statistical package AMOS 24.0 (Analysis of Moment Structure). The data collection technique used a questionnaire with insidential sampling. The parameter estimation results are in accordance with the hypothesis that customer experience significantly affects customer loyalty with a critical ratio (cr) of 4.666 and $P$-Value $* * *$, perceived quality has a positive effect on customer loyalty with a critical ratio (cr) of 5.926 and P-Value ***. From this study it can be learned that in the midst of the Covid-19 pandemic, consumers are still very enthusiastic and loyal to buy Mie Gacoan both online or come to Mie Gacoan outlet even though there are many similar competitors.

Keywords: Customer Experience, Perceived Quality, Customer Loyalty, Mie Gacoan

\section{PENDAHULUAN}

Fase akhir pandemi Covid-19 membuat pertumbuhan ekonomi di Indonesia semakin kuat dan menanjak, banyak bermunculan outlet-outlet makanan dan minuman baru serta aktivitas ukm mulai tumbuh dan bergerak walaupun semua sektor sangat terdampak oleh pandemi covid-19 
yang dimulai pada maret 2020 sampai saat ini masih berlangsung, perusahaan-perusahaan yang bergerak dibidang ritel banyak yang gulung tikar atau bangkrut. Bisnis ritel memerlukan sebuah strategi pemasaran ritel yang handal demi perkembangan usaha dalam jangka panjang yaitu mampu menghasilkan profit yang maksimal serta dapat menciptakan kepuasan pelanggan. Eceran (retailing) meliputi semua kegiatan yang tercakup dalam penjualan barang atau jasa langsung kepada konsumen akhir untuk penggunaan pribadi dan non-bisnis sedangkan pengecer atau retailer adalah setiap usaha bisnis yang volume penjualannya terutama berasal dari eceran. Barang atau jasa tidak dipermasalahkan akan dijual melalui orang, surat, telepon, ataupun mesin penjaja atau dimana barang atau jasa itu dijual baik di toko, di pinggir jalan, atau di rumah konsumen (Kotler dan Keller, 2016:164).

Mie Gacoan merupakan salah satu perusahaan ritel dalam bentuk gerai yang menjual produk berupa olahan mie, dimsum dan berbagai macam minuman. Ada 3 varian mie yang disajikan oleh gerai mie gacoan yaitu mie angel, mie setan, dan mie iblis, untuk olahan dimsumnya sendiri mencakup ceker,siomay, udang keju, udang rambutan, lumpia udang, dan untuk varian minumannya yang sangat digemari oleh pembeli ialah es genderuwo, es pocong, es tuyul dan es sundel bolong, mie gacoan mengambil konsep karakteristik hantu versi Indonesia yang diadaptasi ke menu-menu mereka. Ulasan tentang Mie Gacoan ialah sebuah merk dagang dari jaringan restaurant mie pedas no 1 di indonesia, yang menjadi anak perusahaan PT Pesta Pora Abadi. Berdiri sejak awal tahun 2016, saat ini merk Mie Gacoan telah tumbuh menjadi market leader, utamanya di provinsi Jawa Timur, Jawa Tengah, Jawa Barat, Kepulauan Bali, dan sedang dalam jalur kuat utk berekspansi menjadi merk terbesar nomor 1 secara nasional. Mengusung konsep bersantap modern dengan harga yg affordable, kehadiran "Mie Gacoan" telah mendapatkan apresiasi luar biasa di setiap market dimana "Mie Gacoan" hadir utk melayani puluhan ribu pelanggan setiap bulan nya, Strategi yang tepat bagi gerai ritel modern adalah melalui pemahaman pemasaran yang berorientasi pada pasar yang mensyaratkan pemahaman yang baik mengenai perilaku konsumen, Kehadiran Mie Gacoan yang disambut positif oleh masyarakat Indonesia menumbuhkan banyak pesaing baru yang menawarkan produk sejenis dan juga menghidupkan kembali sensasi makan mie murah di tempat yang cozy yang pernah popular beberapa tahun yang lalu (Adawiyah, et al 2018).

Anggraeni, et al, (2016) mengungkapkan memberikan nilai-nilai yang positif terhadap citra merek yang dibangunnya kepada konsumen dengan meningkatkan, mempertahankan dan menjaga citra merek. Jika citra merek suatu produk positif atau bernilai tinggi maka akan memperngaruhi keputusan konsumen dalam melakukan pembelian terhadap produk tersebut dan sebaliknya jika citra merek suatu produk negatif maka konsumen akan mempertimbangkan untuk melakukan keputusan pembelian, sebagai mana misi dari mie gacoan yaitu Menyediakan produk - produk terbaik dan relevan untuk customer, Menyediakan tempat bersantap sekaligus ruang berkumpul yang nyaman bagi keluarga dan kerabat, Memberikan Customer Satisfaction yang excellent dengan harga sangat affordable. Dalam bisnis ritel hal yang paling penting ialah menjaga konsumen merupakan sebuah keharusan bagi peritel dalam menetapkan strategi bauran ritel. Sundari, et al (2018) menyatakan bahwa unsur-unsur bauran pemasaran ritel adalah lokasi, merchandise, pricing, periklanan dan promosi, atmosfer dalam gerai dan retail service. Pengecer biasanya menggunakan unsur-unsur ini untuk menarik para konsumennya agar membeli produk yang ditawarkannya. Penelitian yang dilakukan oleh Wibisono, et al (2015) juga menyebutkan bahwa faktor-faktor dalam bauran pemasaran ritel adalah, produk, harga, atmosfer toko, dan pelayanan. Konsumen akan memiliki kesan tersendiri dalam pengalamannya berbelanja ketika mereka merasakan berada dalam sebuah gerai. Fenomena pandemi covid-19 membuat pengusaha ritel sangat merugi, masyarakat dihantui ketakutan untuk sekedar keluar rumah untuk membeli makanan, hampir satu tahun pandemi ini berlangsung, keadaan mulai membaik bagi para peritel karena masyarakat mulai aktif beraktifitas kembali, hal ini membuat Mie Gacoan sebagai gerai ritel yang sudah terkenal mulai 
rame lagi, akan tetapi dengan banyaknya pesaing di jenis produk yang sama membuat Mie Gacoan harus berinovasi lebih agar dapat mempertahankan konsumennya. Walaupun sempat diterpa berbagai masalah dengan konsumen maupun pengantar makanan berbasis online mie gacoan tetap eksis di pasar. Berdasarkan uraian sebelumnya maka penelitian ini merumuskan masalah yaitu "Bagaimana pengaruh Customer Experience dan Perceived Quality terhadap Customer Loyalty Pengunjung Mie Gacoan di Kota Semarang”.

\section{TINJAUAN PUSTAKA}

\section{Customer loyalty}

Loyalitas merupakan sikap menyenangi terhadap suatu produk yang direpresentasikan dalam pembelian yang konsisten terhadap produk dengan merek yang sama sepanjang waktu (Kotler, P., dan Keller, K, 2016), Konsumen yang loyal tidak hanya akan mengunakan produk dengan merek yang sama dikemudian hari, namun konsumen yang loyal akan merekomendasikan produk yang pernah dikonsumsinya kepada orang lain. Dalam menjaga loyalitas pelanggan, usaha yang dapat dilakukan oleh perusahaan diantaranya dengan menjaga hubungan baik dengan pelanggan, maupun memberikan reward kepada pelanggan yang telah setia mengkonsumsi produk mereka (Berliana, et al, 2020). Penerapan strategi marketing yang tepat tidak hanya menjadi kunci dalam menjaga loyalitas pelanggan, namun dampaknya lebih jauh dapat menjaga loyalitas karyawan, Indikator Customer loyalty dapat di jelaskan dari 3 hal berikut, pertama ialah mengatakan hal yang positif tentang perusahaan kepada orang lain; kedua ialah merekomendasikan perusahaan kepada orang lain yang meminta saran; ketiga ialah melakukan pembelian ulang di masa yang akan datang (Wibisono, et al, 2015).

Customer loyalty adalah komitmen yang mendalam dari konsumen untuk memiliki hubungan jangka panjang dengan merek atau perusahaan. Salah satu acuan suatu perusahaan yang tetap ingin bertahan hidup dalam usaha yang sedang dijalankan adalah pelangganpelanggan yang loyal. Menurut Kotler, P., dan Keller, K, (2016: 138) "loyalitas adalah sebuah komitmen yang dimiliki pelanggan untuk melakukan pembelian kembali barang atau jasa di masa mendatang meski pengaruh situasi dan usaha pemasaran yang nanti menyebabkan pelanggan beralih". Smith, et al (2002) menjelaskan bahwa "loyalitas pelanggan merupakan komitmen pelanggan dalam bertahan secara mendalam untuk berlangganan kembali atau melakukan pembelian secara berulang". Indikator yang dapat digunakan untuk mengukur Loyalitas pelanggan dapat diukur dengan menggunakan beberapa indikator menurut Wibisono, et al, (2015) diantaranya ialah pembelian ulang, rekomendasi, dan komitmen.

\section{Perceived Quality}

Perceived Quality adalah upaya penciptaan nilai lebih melalui superior performance dari perusahaan. Aaker (2003) mengemukakan bahwa perceived quality sebagai persepsi pelanggan terhadap seluruh kualitas atau keunggulan sebuah produk atau jasa layanan. Berbagai kriteria yang berbeda perlu mendasari dalam penilaian sebuah perceived quality, serangkaian kriteria yang berbeda perlu mendasari dalam penilaian sebuah perceived quality dan terpenting adalah kepuasan yang diperoleh pelanggan. Putri, et al, (2017) mengemukakan ada 8 dimensi dalam menentukan kualitas sebuah perushaan yaitu : Performance (Unjuk Kerja), Durability (Ketahanan), Serviceability (Kemampuan layanan), Aesthetics (Keindahan), Reliability (Kehandalan), Features (fitur).

Perceived Quality adalah besarnya penilaian konsumen terhadap kualitas produk yang diberikan oleh perusahaan, hal ini di pengaruhi oleh besarnya manfaat yang di dapat di bandingkan dengan beasarnya biaya yang di keluarkan oleh konsumen, berikan adalah dimensi- dimensi yang mampu mengukur kualitas sebuah produk jasa Performance (Unjuk 
Kerja): Berhubungan dengan pelayanan dan jasa yang diberikan perusahaan kepada pelanggan, Durability (Ketahanan): Berhubungan dengan jangka waktu atau masa guna barang atau jasa yang digunakan dalam satu periode tertentu, Serviceability (Kemampuan layanan): Kemudahan mendapatkan pelayanan dan Informasi yang di butuhkan oleh pelanggan, Aesthetics (Keindahan): Menyangkut dengan keindahan atau penampilan dan penyajian pelayanan atau jasa. Reliability (Kehandalan): kemungkinan produk atau jasa mampu memenuhi kebutuhan atau keinginan pelanggan sehingga mampu memenuhi cita-cita pelanggan, Features (fitur): Nilai tambah atau innovasi baru yang ditambahkan pada fitur dasar. Sehingga dapat sesuai dengan kebutuhan pelanggan (Putri, et al, 2017).

\section{Customer Experience}

Customer experience adalah upaya mencitakan superior value dimana melalui pengalaman yang di dapat pelanggan menjadi nilai tambah bagi produk. Customer Experience telah menarik perhatian dalam praktek pemasaran sekarang ini. Dimana saat ini sebuah pengalaman di anggap sebuah nilai lebih bagi konsumen. Menurut Smith, et al (2002) idealnya sebuah perusahaan yang ingin menerapkan pengalaman dalam pemasaran mampu memberikan experience yang integral yaitu menyampaikan kelima elemen experience melalui beberapa tahap yaitu Sense adalah dimensi yang berkaitan dengan panca indra, seperti pengalaman melalui penglihatan, suara, sentuhan, rasa dan bau, Feel adalah pengaruh merek kepada konsumen, baik pengalaman yang berhubungan dengan suasana hati maupun pengalaman yang berhubungan dengan emosi, Think adalah mendorong pelanggan agar tertarik dan berpikir secara kreatif, baik pengalaman dalam bentuk inspirasi, teknologi maupun kejutan, sehingga konsumen melakukan evaluasi kembali, Act adalah pola perilaku dan gaya hidup dalam jangka panjang, berdasarkan pengalaman yang terjadi dari interaksi hubungan dengan orang lain, kelompok lain, maupun hubungan dengan kelompok sosial (Wibisono, et al, 2015).

\section{METODE PENELITIAN}

Pelitian menggunakan data primer yang diolah secara kuantitatif. Adapun sumber data dalam penelitian ini menggunakan data primer dan data sekunder. Data primer diperoleh dengan cara survei dan wawancara dengan menggunakan kuisioner dengan skala likert kepada pengunjung Mie Gacoan di kota Semarang yang terletak di Peterongan, Jl. Kompol Maksum 284, Peterongan dan Tembalang Tinjomoyo, Banyumanik, Semarang City, Polulasi dalam penelitian ini adalah pengunjung gerai Mie Gacoan dan teknik pengambilan sampel pada penelitian ini teknik non probability sampling yaitu insidential sampling merupakan teknik yang digunakan untuk penentuan sampel menggunakan pertimbangan tertentu agar sampel tersebut benar-benar dapat mempresentasikan populasi, Teknik analisis data yang digunakan dalam penelitian ini adalah teknik analisis faktor konfirmatori dan maximum likehood estimation pada SEM dan uji asumsi klasik (uji Normalitas, uji Measurement Model, uji Goodness of Fit, dan uji hipotesis) dari dari paket statistik AMOS 24.0 (Analysis of Moment Structure) (Ghozali, 2017). 


\section{HASIL DAN PEMBAHASAN}

\section{Karakteristik Responden}

Karakteristik responden sebagai subjek dalam penelitian ini dapat dilihat dalam Tabel 1.

Tabel 1 Karakteristik Responden

\begin{tabular}{|c|c|c|c|}
\hline No & Karakteristik & Hasil & Presentase \\
\hline \multirow[t]{2}{*}{1.} & Jenis Kelamin & Wanita & $75 \%$ \\
\hline & & Laki-laki & $25 \%$ \\
\hline \multirow[t]{2}{*}{2.} & Usia & $\geq 25$ tahun & $65 \%$ \\
\hline & & $\leq 26$ tahun & $35 \%$ \\
\hline \multirow[t]{2}{*}{3.} & Pekerjaan & Pelajar/Mahasiswa & $74 \%$ \\
\hline & & Pekerja & $26 \%$ \\
\hline \multirow[t]{2}{*}{4.} & Intensitas Kunjungan & $\geq 5 \mathrm{kali} / \mathrm{bulan}$ & $72 \%$ \\
\hline & & $\leq 6 \mathrm{kali} / \mathrm{bulan}$ & $28 \%$ \\
\hline \multirow[t]{2}{*}{5.} & Metode Pembelian & Datang langsung & $73 \%$ \\
\hline & & Pesan online & $27 \%$ \\
\hline
\end{tabular}

Sumber: Data primer yang diolah (2021).

Pada penelitian ini terdapat 100 orang responden sebagai sampel dari populasi pengunjung Mie Gacoan yang terdiri dari pelajar dan pekerja seperti tersaji pada tabel 1 menjelaskan bahwa rata-rata masyarakat di kota Semarang pengunjung gerai Mie Gacoan bisa dibilang sering dalam pembelian kembali ke gerai tersebut walaupun sekarang banyak bertebaran gerai-gerai makanan sejenis, itu menandakan loyalitas konsumen Mie Gacoan cukup tinggi di kota semarang (Setyawan, et. al, 2021)

\section{Uji Normalitas}

Kesimpulan Uji Normalitas dalam penelitian tersaji dalam Tabel 2.

Tabel 2 Assessment of normality

\begin{tabular}{|l|r|r|r|r|r|r|}
\hline Variable & min & max & skew & c.r. & kurtosis & c.r. \\
\hline CE5 & 1,000 & 5,000 &,- 027 &,- 108 &,- 507 & $-1,035$ \\
\hline PQ1 & 2,000 & 5,000 &, 132 &, 539 &,- 449 &,- 916 \\
\hline PQ2 & 2,000 & 5,000 &, 151 &, 616 &,- 594 & $-1,212$ \\
\hline PQ3 & 1,000 & 5,000 &,- 140 &,- 573 &,- 354 &,- 723 \\
\hline PQ4 & 1,000 & 5,000 &,- 029 &,- 117 &,- 063 &,- 130 \\
\hline CL1 & 1,000 & 5,000 &,- 080 &,- 328 &,- 239 &,- 487 \\
\hline CL2 & 1,000 & 5,000 &, 031 &, 128 &,- 481 &,- 982 \\
\hline CL3 & 2,000 & 5,000 &, 032 &, 130 &,- 557 & $-1,137$ \\
\hline PQ8 & 2,000 & 5,000 &,- 028 &,- 114 &,- 705 & $-1,440$ \\
\hline PQ7 & 1,000 & 5,000 &, 010 &, 040 &,- 392 &,- 799 \\
\hline PQ6 & 1,000 & 5,000 &,- 021 &,- 088 &,- 207 &,- 422 \\
\hline PQ5 & 2,000 & 5,000 &, 211 &, 860 &,- 610 & $-1,246$ \\
\hline CE4 & 1,000 & 5,000 &, 082 &, 333 &,- 493 & $-1,007$ \\
\hline CE3 & 1,000 & 5,000 &, 145 &, 593 &,- 368 &,- 750 \\
\hline CE2 & 2,000 & 5,000 &, 277 & 1,132 &,- 492 & $-1,003$ \\
\hline CE1 & 1,000 & 5,000 &,- 216 &,- 883 &,- 457 &,- 932 \\
\hline Multivariate & & & & & 4,286 &, 893 \\
\hline Sub & & & & & \\
\hline
\end{tabular}

Sumber: Data primer yang diolah (2021).

Berdasarkan hasil uji normalitas yang teraji diatas pada Tabel 2 menunjukkan bahwa data terdistribusi dengan normal secara univariate mapupun multivariate dengan nilai critical ratio dari kurtosis tidak ada yang berada pada $\pm 2,58$ dan nilai multivariate yaitu sebesar 0,893 . Data 
yang diolah dapat dikatakan normal apabila memiliki nilai kritis (c.r) yang berada pada $\pm 2,58$ dan hasil uji normalitas data secara univariate dan multivariate menunjukkan nilai masih dalam rentan nilai $\pm 2,58$ (Ghozali, 2017).

\section{Evaluasi Univariate \& Multivariate Outlier}

Mahalanobis Distance guna mengukur ada tidaknya data yang menjadi outlier yaitu dengan melihat skor observasi yang sangat berbeda dengan skor centroid untuk 100 kasus. Pada tabel 3 terlihat jarak minimal mahalanobis yang tertera yaitu sebesar 7,291 serta jarak maksimal ialah 33,055. Data outlier dipersepsikan dari nilai mahalanobis yang melebihi nilai chi-square. Dalam penelitian ini chi - square dari derajat kebebasan 17 (jumlah indikator variabel) pada tingkat signifikansi 0,01 yaitu 33.408 maka dinyatakan tidak terdapat outlier Ghozali (2017) Sebagaimana tersaji pada tabel 3.

Tabel 3 (Mahalanobis distance)

\begin{tabular}{|l|l|l|l|}
\hline Observation number & Mahalanobis d-squared & p1 & p2 \\
\hline $\mathbf{8 1}$ & 33,055 &, 007 &, 518 \\
\hline $\mathbf{3 7}$ & 31,812 &, 011 &, 286 \\
\hline $\mathbf{5 9}$ & 31,508 &, 012 &, 111 \\
\hline $\mathbf{4 0}$ & 30,503 &, 016 &, 071 \\
\hline $\mathbf{9 0}$ & 28,988 &, 024 &, 094 \\
$\mathbf{. . . .}$ & $\ldots \ldots$. & $\ldots \ldots$. & $\ldots \ldots$. \\
\hline $\mathbf{5 5}$ & 9,874 &, 873 &, 003 \\
\hline $\mathbf{7 3}$ & 9,165 &, 906 &, 013 \\
\hline $\mathbf{7 6}$ & 8,761 &, 923 &, 014 \\
\hline $\mathbf{9}$ & 8,441 &, 935 &, 009 \\
\hline $\mathbf{4 7}$ & 7,291 &, 967 &, 036 \\
\hline
\end{tabular}

Sumber: Data primer yang diolah (2021).

\section{Uji Measurement Model}

Dalam penelitian ini, terlihat nilai chi-square $\left(\mathrm{X}^{2}\right)$ dan nilai degree of freedom (df). Berdasarkan hasil uji model penulisan dapat diketahui bahwa chi-square $\left(\mathrm{X}^{2}\right)$ memiliki nilai sebesar 107,106 dan degree of freedom (df) memiliki nilai sebesar 93 seperti yang sudah tersaji pada Tabel 4 dan Gambar 1.

Tabel 4 Kriteria Cut Value Hasil Evaluasi

\begin{tabular}{|l|l|l|l|}
\multicolumn{1}{c}{ Goodness-of-fit indek } & \multicolumn{1}{c|}{ Cut of Value } & \multicolumn{1}{c|}{ Hasil Analisis } & \multicolumn{1}{c|}{ Evaluasi Model } \\
\hline Chi-Square & $($ Kecil $) \leq 116.511$ & 0.870 & Baik \\
\hline Probability & $\geq 0.05$ & 0.051 & Baik \\
\hline GFI & $\geq 0.90$ & 0.885 & Baik \\
\hline AGFI & $\geq 0.90$ & 0.807 & Marginal \\
\hline TLI & $\geq 0.90$ & 0.975 & Baik \\
\hline CFI & $\geq 0.90$ & 0.983 & Baik \\
\hline DF & $\leq 2.00$ & 81 & Baik \\
\hline RMSEA & $\leq 0.08$ & 0.052 & Baik \\
\hline
\end{tabular}

Sumber: Data primer yang diolah (2021).

Hasil pengujian model yang tergambar pada gambar 1 menunjukkan kriteria goodness of fit dalam program AMOS 24 menunjukan bahwa analisis structural equation modeling dalam penelitian ini dapat diterima sesuai dengan model fit dengan nilai Chi-square $=102,870$, Probabilitas $=0,051$ DF $=81$, GFI $=0.885$, AGFI $=0,807$, CFI $=0,975$, TLI $=0,983$ dan RSMEA $=0,052$. Berdasarkan model fit ini dapat disimpulkan bahwa model memenuhi kriteria goodness of fit. Oleh karena itu model persamaan strutural pada penelitian ini cocok dan layak 
untuk digunakan sehingga dapat dilakukan interpresi guna pembahasan lebih lanjut (Ghozali, 2017).

Gambar 1 Model Struktural Penelitian

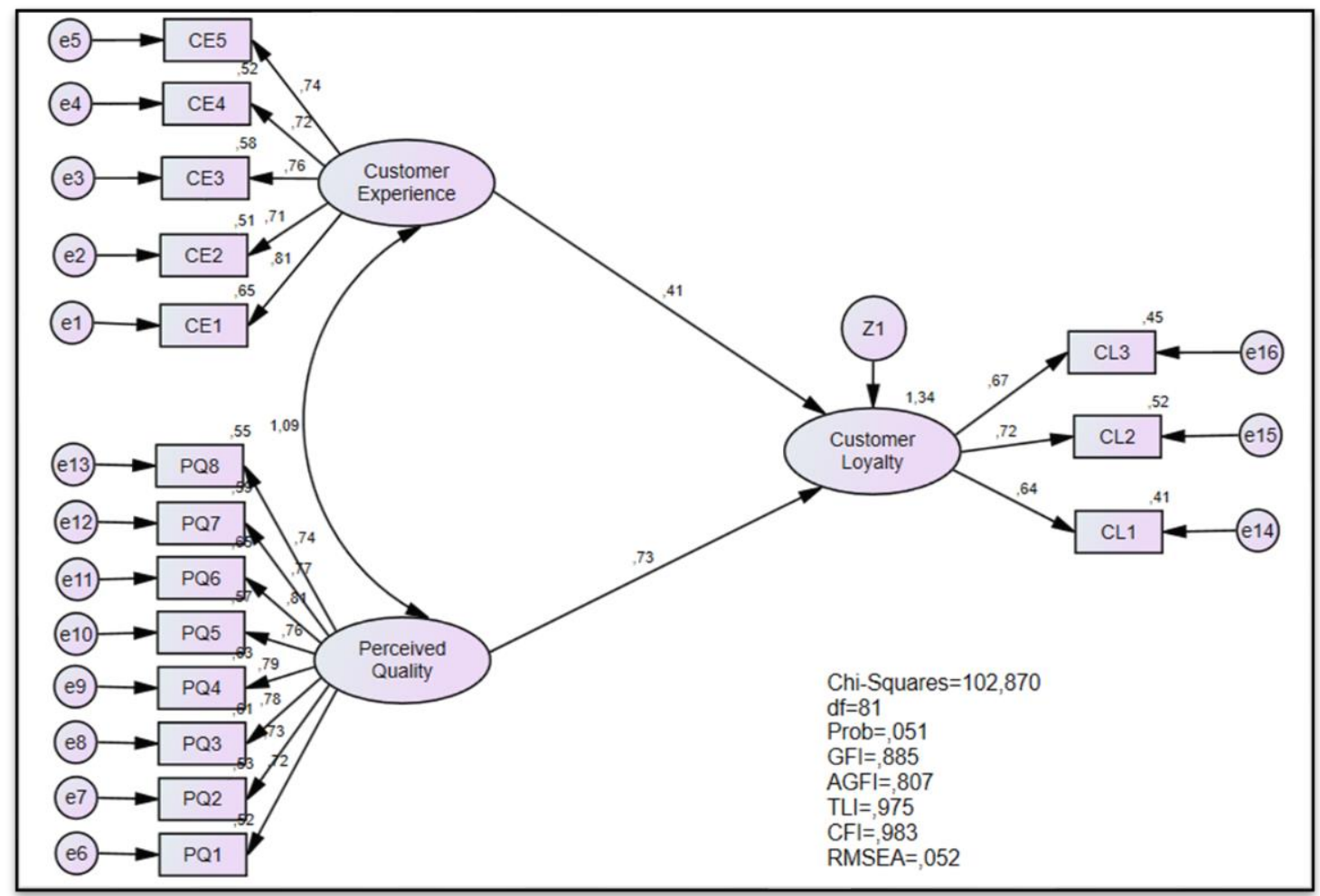

Sumber: Data primer yang diolah (2021).

\section{Uji Hipotesis}

Pada tahap pengujian hipotesis hubungan kausal yang tidak signifikan adalah nilai critical ratio (c.r) memiliki nilai $\mathrm{T}$ kritis yaitu $\geq 1,966$. dalam mempermudah pengambilan keputusan, penulis dapat melihat dari angka probability $(\mathrm{P})$ yang dimana $(\mathrm{P}) \leq 0,05$. Apabila nilai $\mathrm{P} \leq 0,05$ maka $\mathrm{H}_{0}$ diterima, dan apabila sebaliknya jika nilai $\mathrm{P} \geq 0,05$ maka $\mathrm{H}_{0}$ ditolak, pada paket amos hasil uji hipotesis dapat dilihat melalui output regression weights. (Ghozali, 2017) yang tersaji pada tabel 5 .

Tabel 5 Hasil Uji Hipotesis (Regression Weights)

\begin{tabular}{|l|r|l|r|r|r|r|l|l|}
\hline & & Estimate & S.E. & C.R. & \multicolumn{1}{|c|}{ Label } \\
\hline Customer_Loyalty & $<---$ & Customer_Experience &, 300 &, 064 & 4,666 & $* * *$ & par_9 \\
\hline Customer_Loyalty & $<---$ & Perceived_Quality &, 742 &, 125 & 5,926 & $* * *$ & par_10 \\
\hline PQ6 & $<---$ & Perceived_Quality & 1,268 &, 142 & 8,925 & $* * *$ & par_1 \\
\hline PQ7 & $<---$ & Perceived_Quality & 1,136 &, 144 & 7,909 & $* * *$ & par_2 \\
\hline PQ8 & $<---$ & Perceived_Quality & 1,132 &, 128 & 8,819 & $* * *$ & par_3 \\
\hline CL3 & $<---$ & Customer_Loyalty &, 958 &, 135 & 7,098 & $* * *$ & par_4 \\
\hline PQ4 & $<---$ & Perceived_Quality & 1,223 &, 149 & 8,191 & $* * *$ & par_5 \\
\hline PQ3 & $<---$ & Perceived_Quality & 1,212 &, 151 & 8,018 & $* * *$ & par_6 \\
\hline PQ5 & $<---$ & Perceived_Quality & 1,133 &, 146 & 7,785 & $* * *$ & par_7 \\
\hline CL1 & $<---$ & Customer_Loyalty & 1,000 & & & & \\
\hline CL2 & $<---$ & Customer_Loyalty & 1,168 &, 154 & 7,571 & $* * *$ & par_8 \\
\hline PQ2 & $<---$ & Perceived_Quality & 1,061 &, 143 & 7,432 & $* * *$ & par_11 \\
\hline PQ1 & $<---$ & Perceived_Quality & 1,000 & & & & \\
\hline CE1 & $<---$ & Customer_Experience & 1,000 & & & & \\
\hline CE2 & $<---$ & Customer_Experience &, 757 &, 089 & 8,515 & $* * *$ & par_13 \\
\hline CE3 & $<---$ & Customer_Experience &, 855 &, 092 & 9,254 & $* * *$ & par_14 \\
\hline CE4 & $<---$ & Customer_Experience &, 776 &, 090 & 8,608 & $* * *$ & par_15 \\
\hline
\end{tabular}




\begin{tabular}{|l|l|l|r|r|r|r|r|}
\hline CE5 & $<---$ & Customer_Experience &, 843 &, 073 & 11,482 & $* * *$ & par_16 \\
\hline
\end{tabular}

Tabel 6 Hasil Uji Hipotesis (Standardized Regression Weights)

\begin{tabular}{|l|l|l|r|}
\hline Customer_Loyalty & \multicolumn{1}{|c}{ Customer_Experience } & Estimate \\
\hline Customer_Loyalty & $<---$ & Perceived_Quality &, 408 \\
\hline PQ6 & $<---$ & Perceived_Quality &, 729 \\
\hline PQ7 & $<---$ & Perceived_Quality &, 806 \\
\hline PQ8 & $<---$ & Perceived_Quality &, 767 \\
\hline CL3 & ---- & Customer_Loyalty &, 739 \\
\hline PQ4 & $<---$ & Perceived_Quality &, 672 \\
\hline PQ3 & $<---$ & Perceived_Quality &, 794 \\
\hline PQ5 & $<---$ & Perceived_Quality &, 780 \\
\hline CL1 & $<---$ & Customer_Loyalty &, 755 \\
\hline CL2 & $<---$ & Customer_Loyalty &, 642 \\
\hline PQ2 & $<---$ & Perceived_Quality &, 721 \\
\hline PQ1 & $<---$ & Perceived_Quality &, 728 \\
\hline CE1 & $<---$ & Customer_Experience &, 720 \\
\hline CE2 & $<---$ & Customer_Experience &, 808 \\
\hline CE3 & $<---$ & Customer_Experience &, 712 \\
\hline CE4 & $<---$ & Customer_Experience &, 764 \\
\hline CE5 & $<---$ & Customer_Experience &, 723 \\
\hline
\end{tabular}

Hasil output pada Regression Weights dan Standardized Regression Weights menerangkan bahwa setiap indikator atau variabel manifest yang mencerminkan variabel latent memiliki nilai critical ratio (CR) lebih besar (>) dari 1,96 sama dengan nilai t pada regresi (>)1,96 dan P (Probabilitas signifikansi) dengan *** berarti by default signifikan pada 0.001, maka dapat disimpulkan kedua hipotesis diterima.

Hasil penelitian dari variabel Customer Experience, Perceived Quality terhadap Customer Loyalty pada pengunjung gerai Mie Gacoan di Kota Semarang dengan 100 orang responden sebagai sampel dari keseluruhan populasi, diketahui bahwa Customer Experience memiliki pengaruh yang signifikan terhadap Customer Loyalty dengan nilai critical ratio (c.r) sebesar 4,666. Nilai tersebut lebih besar dari ambang batas nilai kritis yaitu sebesar 1,96. Berdasarkan hasil tersebut dapat disimpulkan bahwa variabel Customer Experience memiliki signifikan yang positif atau berpengaruh terhadap Customer Loyalty pengunjung gerai Mie Gacoan di Kota Semarang, selanjunya Perceived Quality menunjukkan adanya pengaruh terhadap Customer Loyalty dengan nilai critical ratio (c.r) 5,926, Berdasarkan hasil tersebut dapat disimpulkan bahwa variabel Perceived Quality memiliki signifikan yang positif atau berpengaruh terhadap Customer Loyalty pengunjung gerai Mie Gacoan di Kota Semarang. Penelitian ini menjelaskan bahwa Customer Experience dan Perceived Quality sangat membantu menjelaskan peningkatan loyalitas konsumen dari Mie Gacoan itu sendiri yang mana sebagian besar adalah generasi milenial dan generasi $\mathrm{Z}$ serta sebagaian generasi Alfa.

\section{KESIMPULAN}

Customer Experience mampu membentuk reputasi ketika pengalaman yang didapat konsumen itu besifat positif maka akan terpatri pada benak konsumen. Pada variabel Customer Experience, responden secara umum setuju bahwa pengalaman yang diberikan oleh Mie Gacoan sesuai dengan reputasi mereka, dengan reputasi mereka selalu menekankan bahwa mereka memberikan pengalaman kuliner yang berkelas dengan harga terjangkau. Perceived Quality dapat dirasakan, sehingga membentuk image yang berbeda. Pengaruh pesepsi kualitas terhadap kepuasan konsumen sebenarnya dapat dilihat dengan kemudahan yang kita dapat, 
fasilitas, layanan pegawai, serta pengalaman-pengalaman kuliner yang baru, pernyataan ini sesuai dengan penelitian yang dilakukan Wibisono, et al (2015) bahwa Perceived Quality sangat berpengaruh terhadap reputasi suatu perusahaan sehingga meningkatkan loyalitas pelanggan. Reputasi berkenaan dengan opini dari orang lain bahwa merek itu baik dan dapat diandalkan (reliable). Dengan adanya persepsi kaulitas positif, dapat membangun reputasi yang positif, apabila perusahaan mampu memenuhi anggapan tersebut. pada penelitian ini memnujukkan bahwa Mie Gacoan sudah mampu memenuhi persepsi kualitas dibenak konsumen, hal ini dibuktikan dengan pesetujuan dari responden tentang kualitas yang dimiliki oleh Mie Gacoan, dari sistem yang mereka miliki, metode berbelanja, kemudahan pembayaran, fasilitas yang dimiliki serta pelayanan yang diberikan telah dipenuhi oleh Mie Gacoan, sehingga hal ini membentuk reputasi dari Mie Gacoan. Reputasi menjadi salah satu keunggulan Mie Gacoan dibandingkan dengan pesaing-pesaing mereka saat ini. Hal inilah yang membuat konsumen menjadi loyal karena kepada Mie Gacoan, selain itu adanya Emosional brand yang di dapat, inilah yang membangaun konsumen untuk loyal. Dimana mereka merasa ada kebanggan tersendiri ketika berkunjung maupun membeli Mie Gacoan secara online. konsumen Mie Gacoan bisa mengupload ke media sosial yang mereka inginkan dengan bangga bisa membeli produk Mie Gacoan dengan harga murah tapi kualitas premium, hal ini selaras dengan penelitian yang dilakukan Sundari, et al (2018) bahwasanya untuk membangun loyalitas pelanggan diperlukan citra merek yang sesuai dengan keinginan konsumen.

Peneliti selanjutnya mungkin bisa menambah variabel bebas (X). Variabel bebas dapat berupa Aggresive Promotion, maupun variabel lainnya yang mana variabel baru tersebut dapat meningkatkan kuantitas konsumen Mie Gacoan, sehingga Mie Gacoan dapat memperoleh konsumen baru, tetapi juga tetap mempertahankan konsumen lama. Penelitian ini dapat pula diterapkan untuk perusahaan-perusahaan yang berfokus pada kualitas, layaknya Cafe, Restaurant, Perhotelan, dan sejenisnya.

\section{DAFTAR PUSTAKA}

Aaker, David A. (2003). “The Power of Branded Diferentiator" dalam MIT Sloa Management Review. Vol. 45, No. 1:85-86. London : Cambridge Univ.

Adawiyah, S. R. A., \& Wulandari, A. (2016). Pengaruh Brand Image Terhadap Keputusan Pembelian Pada Mie Gacoan, 14-19.

Anggraeni, D. P., Kumadji, S., \& Sunarti. (2016). Pengaruh Kualitas Produk Terhadap Kepuasan dan Loyalitas Pelanggan, 37(1).

Berliana, M., \& Zulestiana, D. A. (2020). Pengaruh E-Service Quality terhadap Customer Satisfaction dan Loyalty pada Pengguna Gopay di Indonesia, 4(2), 11-17.

Ghozali, I. (2017). Model Persamaan Struktural Konsep dan Aplikasi Dengan Program AMOS 24 Update Bayesian SEM ( $7^{\text {th }}$ ed). Semarang: Undip

Kotler, P., dan Keller, K. (2016). Marketing Management (15 ${ }^{\text {th }}$ ed). Edinburgh Gate, Harlow, England: Pearson Education.

Putri, Y. L., \& Utomo, H. (2017). Pengaruh Kualitas Pelayanan Terhadap Loyalitas Pelanggan Dengan Kepuasan Sebagai Variabel Intervening, 10(19), 70-90.

Rita, P., Oliveira, T., \& Farisa, A. (2019). Heliyon The impact of e-service quality and customer satisfaction on customer behavior in online shopping. Heliyon, 5(October), e02690. https://doi.org/10.1016/j.heliyon.2019.e02690

Setyawan, NA., Wibowo BY., , \& Ayuwardani M. (2021). Analysis Of Entrepreneurship Interest On Business Productivity, Jurnal Sains Sosio Humaniora 5 (1), 628-639, https://doi.org/10.22437/jssh.v5i1.14787

Schmitt, Bernd. H. (2003). Customer Experience Management. John Wiley \& Sons, Inc.

Smith, Shaun \& Wheeler, Joe. (2002). Managing The Customer Experience. Prentice hall. 
Sundari, P., \& Dewi, A. (2018). Membangun Loyalitas Pelanggan melalui Kepuasan yang dipengaruhi oleh Kualitas Produk, (Studi Pada Produk Smartphone Merek Oppo), 8798.

Wibisono, T., \& Dharmayanti, D. (2015). Pengaruh Market Orientation Terhadap Customer Loyalty dengan Customer Experience dan Perceived Quality sebagai Variabel Perantara serta Brand Reputation sebagai Variabel Intervening di English First Surabaya, 1(1), 111. 